\title{
Growth of side shoots in brussels sprout plants as influenced by $\mathrm{GA}_{3}$ and defoliation
}

\author{
H. G. Kronenberg
}

Department of Horticulture, Agricultural University, Wageningen, the Netherlands

Received: 19 January 1973

\section{Summary}

At ten different dates between May and September field-grown brussels sprout plants were treated with $\mathrm{GA}_{3}$ or defoliated. Both treatments stimulated side shoot growth to about the same extent but with a maximum at different moments of the year: $\mathrm{GA}_{3}$ at 8 June, defoliation at 3 August. The defoliation effect is in fair agreement with earlier research. $\mathrm{GA}_{3}$ is not an antagonist of the growth-retarding compound of the brussels sprout plants.

\section{Introduction}

Side shoots of brussels sprout plants normally develop into loose sprouts, 'roses', early in the season and into firm sprouts later. In early varieties longer side shoots develop sometimes rather early in the season. These phenomena lead to the suggestion that growth of side shoots is more and more retarded during the growing season (Kronenberg, 1971). The experiment described below tried to gather information about the character of this retardation mechanism. Two hypotheses were tested. The first was that gibberellic acid may interfere with the retardation, so fortnightly applications of $\mathrm{GA}_{3}$ were tried. The second hypothesis was that if this retardation is built up during the season the leaves may play a role and defoliation every fortnight during the growing season can give interesting results.

\section{Materials and methods}

The plants used in the experiments were propagated vegetatively in the same way as described earlier (Kronenberg, 1967). Bud cuttings were taken 1 March 1971 from a brussels sprout clone, which originated from a selected plant of variety 'Sandra', inserted in peat moss and rooted at $21^{\circ} \mathrm{C}$. The young plants were potted $29 \mathrm{March}$, later brought into the open and planted on the field 10 May at $60 \times 60 \mathrm{~cm}$. There were 5 treatments: application of $0,3,9$ and $27 \mathrm{mg} \mathrm{GA}_{3}$, defoliation and a control on 10 different dates, starting 25 May 1971 and repeated fortnightly (see Fig. 2). The $0 \mathrm{mg}$ $\mathrm{GA}_{3}$ meant application of water only; control was no treatment at all. As each plot

Publication 384, Laboratorium voor Tuinbouwplantenteelt, Landbouwhogeschool, Wageningen, the Netherlands. 


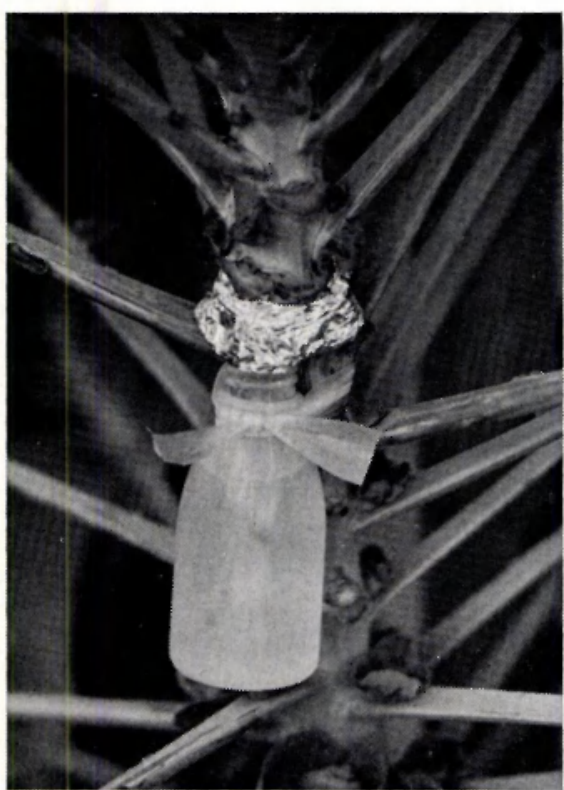

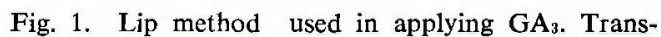
piration from the flask was reduced by the use of aluminium foil.

contained 5 plants, there were 300 plants in the field.

It is rather difficult to apply $\mathrm{GA}_{3}$ quantitatively to sprout plants, because these have a very waxy cuticula. Therefore the lip method was used (Fig. 1). A longitudinal slid was made into the stem so that a lip was formed about $8 \mathrm{~cm}$ long and $0.5 \mathrm{~cm}$ thick, which was brought into a plastic flask with a $\mathrm{GA}_{3}$ solution. Preliminary experiments had shown that such a lip would take up $6 \mathrm{ml}$ in 2-10 hours. The solutions in the flask contained 0, 3, 9 and $27 \mathrm{mg} \mathrm{GA} 3$ per $6 \mathrm{ml}$. After the lips had taken up this amount they were bound into their original position with a rubber band and grew together with the stem again in due time.

Defoliation meant that all leaves longer than $4 \mathrm{~cm}$ were broken away.

During the growing season plants received the normal cultural cares. From the moment that growth had stopped in the beginning of December all side shoots longer than $2 \mathrm{~cm}$ were measured and the average lengths determined. Normally every plot of 5 plants produced about 450 side shoots.

\section{Results and discussion}

The results of the experiments are shown is Fig. 2. Application of $\mathrm{GA}_{3}$ as well as defoliation influenced sprout lengths measured at the end of the growing season. If the results are arranged in the way of Fig. 2 it is clear that these influences were different in the 10 treatments. The higher the amount of $\mathrm{GA}_{3}$ the longer the side shoots, particularly in the treatments between 8 June and 3 August.

The influence of $\mathrm{GA}_{3}$ is most pronounced at the beginning of the season with a maximum in the 8 June treatment. From then on the effect gradually declines; from 17 August onwards there is very little effect of $\mathrm{GA}_{3}$ (Fig. 3). 


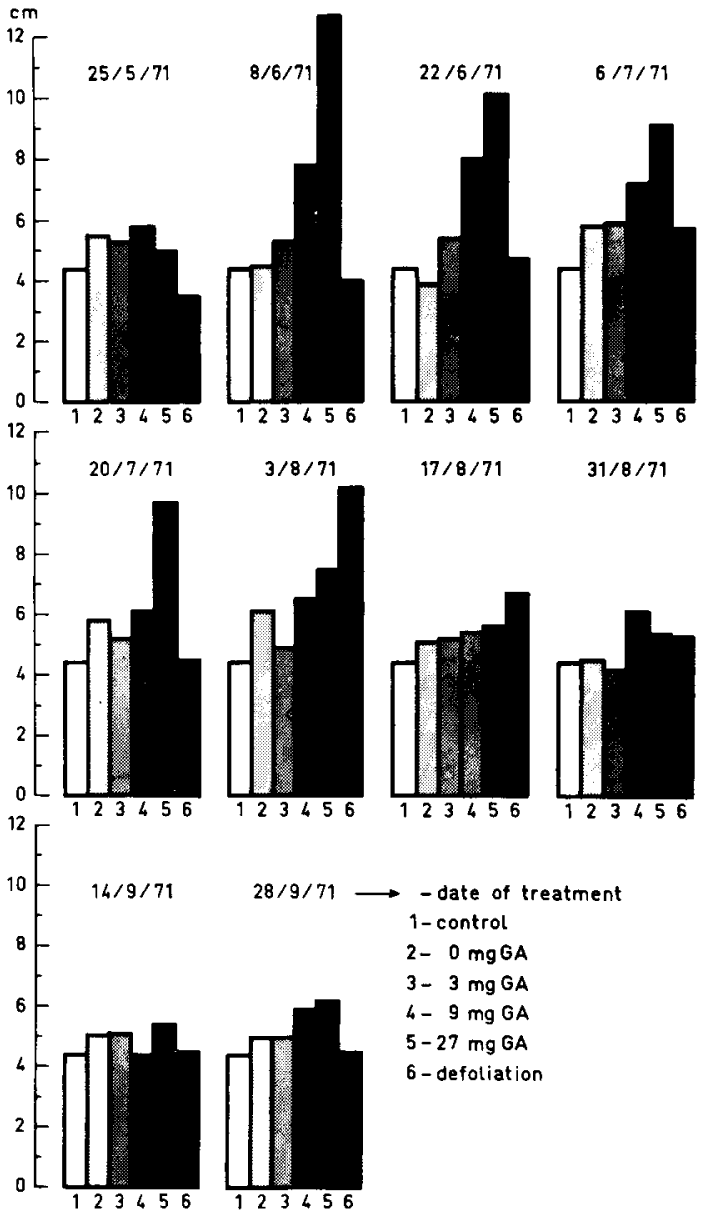

Fig. 2. Average lengths of side shoots of brussels sprout plants measured at the end of the growing season after $\mathrm{GA}_{3}$ application or defoliation on 10 dates.

Defoliation had quite another influence. Normally, removing the leaves means a poorer growth and all defoliated plants are of the same length as or shorter than the controls. Side shoot growth, however, is stimulated by defoliation from the third to the ninth treatment. In the first part of the series there is an increasing stimulation (Fig. 3). In the 3 August treatment the stimulation is at a maximum. In later series influence is decreasing. It is clear that the absence of the leaves is the cause of this different growth behaviour. Obviously the normally occurring growth retardation of the side shoots of brussels sprout plants is induced by the leaves. The leaves produce a growth-retarding substance.

For these results the following explanation can be offered. If the leaves are taken away early in the season new leaves are formed immediately on the plants which inhibit the side shoots, so that their growth is about normal $(=$ control $)$. The later the defoliation, the more leaves are taken away, the more side shoot growth differs from the control. This explains the rising part of Fig. 3 (to a maximum). To explain the 


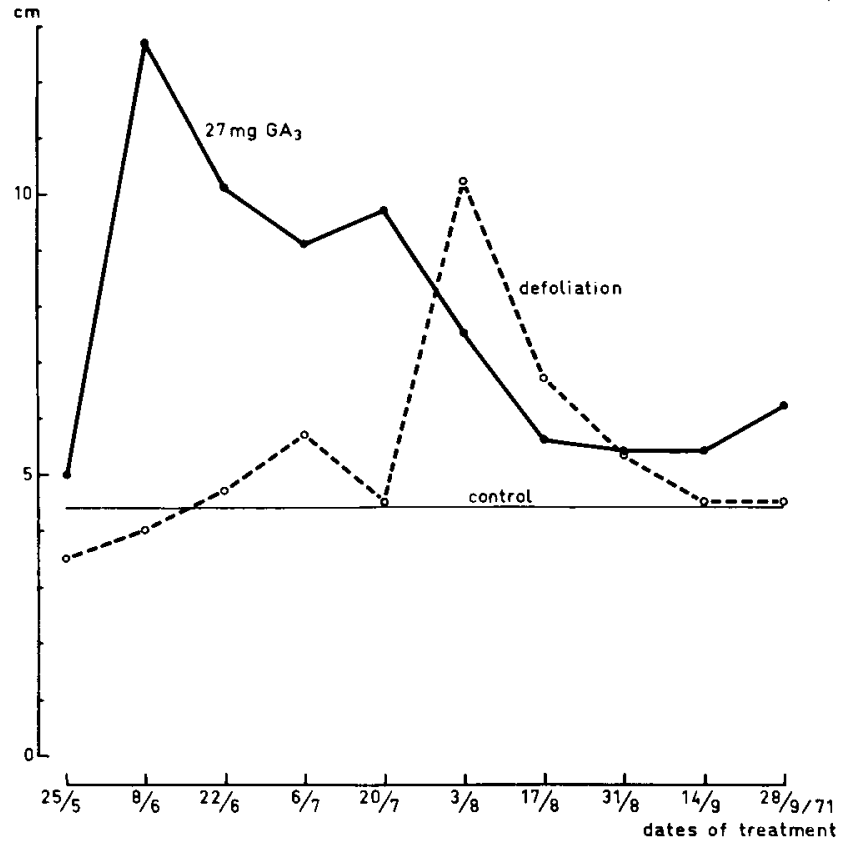

Fig. 3. Average lengths of side shoots of brussels sprout plants measured at the end of the growing season as influenced by application of $27 \mathrm{mg} \mathrm{GA}_{3}$ (drawn line) or defoliation (dotted line) in the course of the growing season.

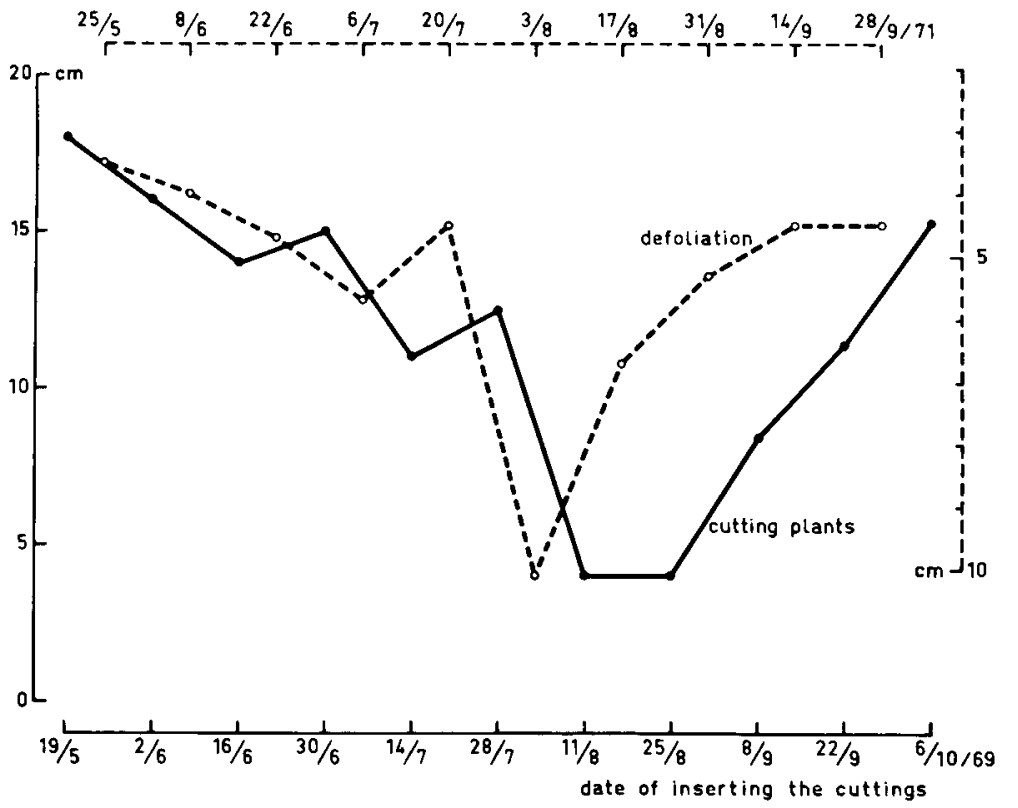

Fig. 4. Lengths of 12-week-old sprout plants from bud cuttings (drawn line) and lengths of side shoots of brussels sprout plants after defoliation (dotted line, graph inverted). 
second part of the reactions, after 3 August, an additional hypothesis is needed. Taking away of the leaves in these months has less and less influence on side shoot growth. This means that the leaves are less and less active in producing a growthretarding substance. Now the compound has already been transported into the thick stem and growth of side shoots is more and more determined by this stored substance than by the newly made.

These growth reactions of the side shoots are in good agreement with the results of former experiments (Kronenberg, 1971). If the results of growth of young plants from cuttings are brought together with the present results of shoot growth after defoliation, the lines have nearly the same shape and coincide (Fig. 4).

The maximum growth stimulation after defoliation (3 August 1971) coincides with the minimum elongation activity in cutting plants (11 August 1969): the mechanisms which are responsible for both reactions of the plants seem to be the same.

The differences between the reactions of brussels sprouts to the application of $\mathrm{GA}_{3}$ and to defoliation at different moments in the season (the differences between the graphs of Fig. 2) clearly mean that the plants are influenced in a different way; $\mathrm{GA}_{3}$ application does not interfere with activities of a growth-retarding substance. $\mathrm{GA}_{3}$ is not the antagonist of the growth-retarding compound of the brussels sprout plants.

\section{References}

Kronenberg, H. G., 1967. Vegetatieve vermeerdering van spruitkool. Meded. Dir. Tuinb. 30: 314-315. Kronenberg, H. G., 1971. Growth retardation in side shoots of brussels sprout plants. Neth. J. Agric. Sci. 19: 102-103. 